\title{
Maternal uniparental disomy for chromosome 14
}

\author{
I K Temple, A Cockwell, T Hassold, D Pettay, P Jacobs
}

\begin{abstract}
We report the first case of maternal uniparental disomy of chromosome 14 in humans. The male proband inherited a balanced 13;14 Robertsonian translocation from his mother. Molecular studies showed that neither chromosome 14 was of paternal origin. The proband is of above average intelligence, but he has hydrocephalus, a bifid uvula, premature puberty, short stature, and small testes. It is not known if the clinical findings are related or coincidental to the uniparental disomy.
\end{abstract}

In 1980 Engel $^{1}$ recognised that, because of the relatively large proportion of human gametes that have an additional or missing chromosome, there was a possibility of fertilisation involving two complementary aneuploid gametes resulting in a euploid conceptus in which both members of one chromosome pair came from the same parent. He called this phenomenon uniparental disomy. Later in the same year the first two examples of uniparental disomy were described. ${ }^{3}$ Both were women referred for recurrent abortions who were found to have a Robertsonian translocation $t(22 ; 22)$ that had been inherited from their phenotypically normal mother. These exceptional women must have arisen by the fertilisation of an egg carrying the translocation by either a sperm nullisomic for chromosome 22 or by a normal sperm, the resulting trisomy 22 conceptus losing the paternal 22 very early in development. Both women were phenotypically normal and it can therefore be concluded that maternal uniparental disomy

Wessex Regional Genetic Counselling Unit, Department of Child Health, University of Southampton, Southampton General Hospital, Tremona Road, Southampton SO9 4XY.

I K Temple

Wessex Regional Genetics Laboratory, Salisbury General Hospital, Salisbury SP2 7SX.

A Cockwell, P Jacobs

Department of Pediatrics, Emory University Medical School, Atlanta, Georgia, USA.

T Hassold, D Pettay

Correspondence to Dr Jacobs.

Received for publication 26 March 1991.

Accepted for publication 15 April 1991. for chromosome 22 is not associated with any major developmental disability. Carpenter $e t a l^{4}$ described a child with developmental and language delay who was homozygous for a pericentric inversion of chromosome 4 for which the mother was heterozygous. This child may also be a uniparental disomic. More recently Nicholls et $a l^{5}$ reported six cases of maternal uniparental disomy for chromosome 15 in patients with Prader-Willi syndrome and in at least one case the mother had a 13;15 Robertsonian translocation and her affected child had inherited both the translocation and the normal chromosome 15 from his mother. Malcolm $e t a l^{6}$ reported two cases of paternal uniparental disomy for chromosome 15 among 26 chromosomally normal patients with Angelman's syndrome. Wang et $a l^{7}$ reported a mentally retarded girl who had multiple congenital abnormalities and was a paternal uniparental disomic for chromosome 14, her father having a Robertsonian translocation involving chromosomes 13 and 14 and her mother a reciprocal translocation between chromosomes 1 and 14. Two isolated cases of cystic fibrosis who also had growth retardation have both been shown to be maternal uniparental disomics for chromosome 7.89

In a series of experiments with mice carrying translocations, Cattanach and his colleagues ${ }^{10} \mathrm{li}$ showed that uniparental disomy for different chromosomes had quite different effects. Both maternal and paternal uniparental disomics for chromosomes 1, 4, $5,9,13,14$, and 15 of the mouse appear normal, whereas uniparental disomics for chromosomes 2,6 , $7,8,11$, and 17 do not. Chromosomes or chromosome regions containing genes whose expression differs depending on whether they are maternally or paternally derived are said to be imprinted. The phenotypic effect of such imprinting covers a wide spectrum. For example, paternal uniparental disomy for chromosome 6 in the mouse has no phenotypic effect whereas maternal uniparental disomy is lethal. Both maternal and paternal disomy for chromosome 2 in the mouse are associated with developmental abnormality, but the abnormal phenotypes depart from normal in opposite directions.

Uniparental disomy can result from fertilisation of a gamete disomic for a chromosome by a gamete nullisomic for the same chromosome ('gamete complementation') or by a loss or gain of a chromosome from a trisomic or monosomic conceptus ('aneuploid correction'). ${ }^{12}$ Therefore, any situation 
that predisposes to the formation of aneuploid gametes will also predispose to uniparental disomy. One population that is known to be at a high risk of producing gametes with an additional or missing chromosome are carriers of Robertsonian translocations. We have therefore instituted a systematic search for uniparental disomy among patients with unexplained developmental abnormalities who have an apparently balanced Robertsonian translocation. Twenty-two such patients have been identified by the Wessex Regional Genetics Laboratory and to date we have reinvestigated only two and found one, the subject of this report, to be a maternal uniparental disomic for chromosome 14.

\section{Case report}

The proband was the first child of unrelated Caucasian parents. The pregnancy progressed uneventfully until the onset of spontaneous labour at 32 weeks. Delivery was by caesarian section for fetal distress. At birth his weight was $1430 \mathrm{~g}$ (25th centile) and his head circumference $28 \mathrm{~cm}$ (10th centile). Apgar score was 7. He had a cyanotic episode within a few hours of birth and was given antibiotics. Cultures were all negative. He did not require ventilation but his head circumference increased rapidly in size and by 10 days was $31 \mathrm{~cm}$ (50th centile) and by 2 months was $36.3 \mathrm{~cm}$ ( $>97$ th centile). The hydrocephalus arrested spontaneously and a shunt was unnecessary. Early motor milestones were delayed. He sat at 12 months and took his first steps at $\mathbf{1 7}$ months and now has poor motor coordination. His speech, however, was advanced with several words by the age of 12 months. His intellectual development has remained good. He attends a normal school and is likely to go on to university education.

At the age of 4 years he had bilateral orchidopexy for undescended testes. A scoliosis (concave to the right) was noted in the first year of life which progressed rapidly and required the insertion of Harrington rods at the age of 12 years. Spinal $x$ rays showed block vertebrae at T5/6.

His growth was initially normal. His height at 7 years $(117 \mathrm{~cm})$ and 8 years $(122 \mathrm{~cm})$ was between the 10 th and 25 th centiles. He went into puberty at the age of 10 and had a corresponding growth spurt, but there has been little growth since the age of 12 years and at 15 years his standing height was $154.7 \mathrm{~cm}$ $(<3$ rd centile), sitting height $79.3 \mathrm{~cm}(-3.5 \mathrm{SD}$ below the mean), and subischial leg length $75.4 \mathrm{~cm}(-1.0$ SD below the mean). A hand $x$ ray at this time showed complete fusion of epiphyses. He was reinvestigated neurologically at 15 years of age because he developed a fine resting tremor. A CT scan confirmed hydrocephalus affecting the lateral and third ventricles. The fourth ventricle was within normal limits.

On examination at age 17 his appearance was dominated by the discrepancy between his height and the size of his head. He had a prominent forehead and supraorbital ridges. His philtrum was short and his mouth downturned (fig 1). His teeth were normal but the palate was high and short with a bifid uvula. Speech was high pitched and nasal in quality. Hair growth on the head and face was normal. Examination of the eyes and ears was normal, as were hearing and vision.

His hands and feet were small and slender with fifth finger clinodactyly and normal nails. He had a mild scoliosis. There was truncal obesity but his arms and legs were thin. The nipples were widely spaced and pigmented. Secondary sexual hair had developed normally. Pubic hair was Tanner stage 5 and his genitalia were relatively small. His penile length was $10 \mathrm{~cm}$ (10th centile) and testicular volume on both the left and right sides was $8 \mathrm{ml}(<3$ rd centile). Neurological examination showed normal cranial nerves but a mild, right sided hemiplegia. In addition, he had a fine tremor more marked in the left hand. Testosterone, thyroxine, TSH, and LH/FSH levels were normal as were his electrolytes.

The proband has a normal brother. His mother's height is $160 \mathrm{~cm}$ and his father's height $190 \mathrm{~cm}$. There is no other family history of relevance and no history of miscarriages.

\section{Laboratory investigations and results}

Chromosome studies of peripheral blood leucocytes showed the father to have a normal chromosome

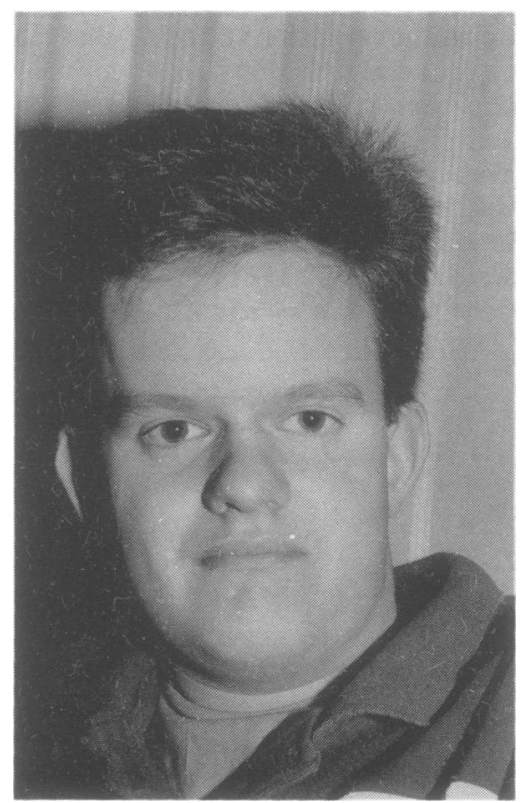

Figure 1 Photograph of the proband at 17 years. Note the prominent forehead, short philtrum, and downturned mouth. 
The inheritance of chromosome 13 and 14 polymorphic markers.

\begin{tabular}{|c|c|c|c|c|c|c|}
\hline Locus & Probe & Location & Enzyme & Proband & Father & Mother \\
\hline & $\begin{array}{l}\text { Cytogenetic } \\
\text { polymorphisms }\end{array}$ & $\operatorname{cen} / p$ & & $a, t(13 q 14 q)$ & $a, b$ & $c, t(13 q 14 q)$ \\
\hline \multirow[t]{2}{*}{$\begin{array}{l}D 13 Z 1 \\
D 13 S 1 \\
D 13 S 3 \\
D 13 S 11 \\
D 13 S 5 \\
D 13 S 2 \\
D 13 S 2 \\
D 13 S 7 \\
D 13 S 49 \\
D 13 S 39\end{array}$} & $\begin{array}{l}\alpha R 1680 \\
\text { p7F12 } \\
\text { p9A7 } \\
\text { p9A7 } \\
\text { pHUB8 } \\
\text { p9D11 } \\
\text { p9D11 } \\
\text { pHU26 } \\
\text { pCMI40 } \\
\text { pTH162 }\end{array}$ & $\begin{array}{l}\text { cen } \\
\text { q12-14 } \\
\text { q21-34 } \\
\text { q21-34 } \\
\text { q22-34 } \\
\text { q22 } \\
\text { q22 } \\
\text { q22 } \\
\text { q } \\
\text { q }\end{array}$ & $\begin{array}{l}\text { TaqI } \\
\text { MspI } \\
\text { HindIII } \\
\text { MspI } \\
\text { HindIII } \\
\text { TaqI } \\
\text { MspI } \\
\text { BgIII } \\
\text { TaqI } \\
\text { BgIII }\end{array}$ & $\begin{array}{l}1,1 \\
1,1 \\
1,1 \\
2,2 \\
1,2 \\
1,2 \\
1,1 \\
1,1 \\
\text { A,B } \\
2,3\end{array}$ & $\begin{array}{l}1,1 \\
1,2 \\
1,1 \\
2,2 \\
1,2 \\
2,2 \\
1,1 \\
1,2 \\
\text { A,A } \\
2,3\end{array}$ & $\begin{array}{l}1,2 \\
1,2 \\
1,1 \\
2,2 \\
1,1 \\
1,2 \\
1,1 \\
1,1 \\
\text { A,B } \\
2,3\end{array}$ \\
\hline & $\begin{array}{c}\text { Cytogenetic } \\
\text { polymorphisms }\end{array}$ & $\operatorname{cen} / \mathbf{p}$ & & $c, t(13 q 14 q)^{*}$ & $a, b$ & $c, t(13 q 14 q)$ \\
\hline $\begin{array}{l}D 14 S 1 \\
D 14 S 23 \\
D 14 S 20 \\
D 14 S 22 \\
D 14 S 19 \\
D 14 S 16\end{array}$ & $\begin{array}{l}\text { pAW101 } \\
\text { cKKA39 } \\
\text { pMCOC12 } \\
\text { pCMM66 } \\
\text { pHHH208 } \\
\text { pTHH37 }\end{array}$ & $\begin{array}{l}\mathrm{q} 32.32-32.33 \\
\mathrm{q} 32.33-32.33 \\
\mathrm{q} 32.33 \\
\mathrm{q} \\
\mathrm{q} \\
\mathrm{q}\end{array}$ & $\begin{array}{l}\text { EcoRI } \\
\text { MspI } \\
\text { MspI } \\
\text { PstI } \\
\text { BamHI } \\
\text { PstI }\end{array}$ & $\begin{array}{l}\mathbf{A}, \mathbf{A} \\
\mathbf{C}, \mathbf{C}^{*} \\
\mathbf{B}, \mathbf{B}^{*} \\
\mathbf{A}, \mathbf{A} \\
3,3 \\
2,2\end{array}$ & $\begin{array}{l}\text { A,B } \\
\text { A,B } \\
\text { A,A } \\
\text { A,B } \\
1,3 \\
1,2\end{array}$ & $\begin{array}{l}\text { A,B } \\
\text { A,C } \\
\text { B,B } \\
\text { A,A } \\
3,3 \\
2,2\end{array}$ \\
\hline
\end{tabular}

${ }^{*}$ No paternal alleles present.

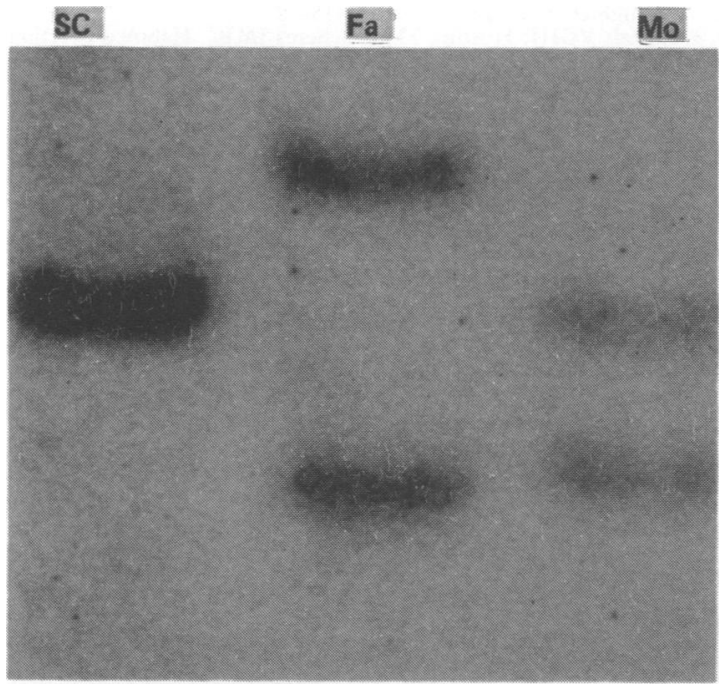

Figure 2 Southern blot of probe cKKA39 (recognising locus DI4S23), showing absence of a paternally derived allele.

constitution while both the proband and his mother had 45 chromosomes and a Robertsonian translocation involving chromosomes 13 and 14 . Fluorescent polymorphisms were examined and the results suggested that the proband had inherited his single free chromosome 13 from his father, but his single free chromosome 14 , as well as the translocation, from his mother (table).

The inheritance of 10 probes that recognise loci on chromosome 13 and six probes that recognise loci on chromosome 14 were studied. ${ }^{1314}$ As can be seen from the table, given that the proband has inherited his 13;14 translocation from his mother, he must have inherited his free chromosome 13 from his father because at locus D13S5 he has inherited a paternal allele that is not present in his mother. The situation is different for chromosome 14 where he has not inherited paternal alleles for loci D14S20 or D14S23. Furthermore, the results of all four other chromosome 14 loci tested are compatible with the proband having inherited both the translocation and the free chromosome 14 from his mother, there being no paternal chromosome 14 . We also considered the possibility that he might have inherited a paternally derived chromosome 14 with a microdeletion. However, dosage studies of the same filters sequentially hybridised to chromosome 14 and chromosome 21 probes indicated that he had two copies of the chromosome 14 loci studied.

The proband appeared to be homozygous for all six chromosome 14 probes tested, including the only two for which his mother was heterozygous. Both these latter probes recognise loci at the distal tip of the long arm. Their reduction to homozygosity suggests that the free maternal chromosome 14 paired with the translocation chromosome during pachytene and underwent at least one exchange between the centromere and the loci D14S1 and D14S23. Thus, nondisjunction in this patient was not associated with failure of pairing or exchange.

Paternity was checked using multiallelic probes that recognise loci D16S7 and D21S112 and the results were consistent with the legal father being the biological father. 


\section{Discussion}

The most plausible interpretation of our results is that the proband is a maternal uniparental disomic for chromosome 14. What is less clear is whether his present clinical problems of short stature, hydrocephalus, scoliosis, nasal speech, bifid uvula, and small testes are caused by this finding or are coincidental to it. Abnormalities of growth have been recognised in other examples of uniparental disomy in both humans ${ }^{89}$ and in mice. ${ }^{10}$ However, the proband's short stature might be the result of premature puberty complicated by a progressive scoliosis further reducing truncal height. This suggestion is supported by two prepubertal height recordings within the normal range. Early puberty itself may be related to uniparental disomy of chromosome 14 , but in the proband this could be secondary to hydrocephalus. Similarly, a bifid uvula may be significant or coincidental. One unexplained finding was his small testicular volume despite normal genital and secondary sexual hair development. Both testes were well positioned in the scrotal sac after an orchidopexy at 4 years. It is unlikely that the subsequent failure of testicular enlargement is related to the operation, which could also not explain the failure of the testes to descend initially. What is clear, however, is that despite prematurity, a stormy neonatal course, and subsequent hydrocephalus, the proband is of normal intelligence which suggests that maternal uniparental disomy for chromosome 14 is compatible with normal intellectual development.

We are currently looking at persons with maternally inherited Robertsonian translocations involving chromosome 14, both phenotypically normal and abnormal, in order to determine whether or not chromosome 14 shows an imprinting effect. The only previously described patient with uniparental disomy for chromosome 14 was a paternal uniparental disomic and she had mental retardation and multiple congenital abnormalities. ${ }^{7}$ Again, it is impossible to know whether her phenotypic abnormalities are causal or coincidental to her paternal uniparental disomy.

The proximal part of chromosome 14 in man is homologous to chromosome 14 in the mouse, while the more distal part is homologous to mouse chromosome $12 .{ }^{15}$ Both maternal and paternal uniparental disomies for mouse chromosome 14 are known and neither is associated with any phenotypic effect. However, the status of both maternal and paternal uniparental disomies for mouse chromosome 12 is not known. If the abnormal phenotypes described by Wang $\mathrm{et}^{\mathrm{al}} \mathrm{l}^{7}$ and by ourselves are found to be caused by uniparental disomy, chromosome 14 must, like chromosome 15, show an imprinting effect for both paternally and maternally inherited chromosomes, the effect being very different for the two types of disomy. If, however, the phenotypes turn out to be coincidental to the disomy it will indicate that human chromosome 14 is not imprinted, at least not in a way that interferes with normal growth and development.

We are grateful to Dr $P$ Betts for referring the patient to us and to $\operatorname{Dr} N$ Dennis for his help and encouragement. This work was supported in part (TH, DP) by grant HD.21341 from the National Institutes of Health.

1 Engel E. A new genetic concept: uniparental disomy and its potential effect, isodisomy. Am f Med Genet 1980;6:137-43.

2 Palmer CG, Schwartz S, Hodes ME. Transmission of a balanced homologous $t(22 q ; 22 q)$ translocation from mother to normal daughter. Clin Genet 1980;17:418-22.

3 Kirkels VGHJ, Hustinx TWJ, Scheres JMJC. Habitual abortion and translocation $(22 \mathrm{q} ; 22 \mathrm{q})$ : unexpected transmission from a mother to her phenotypically normal daughter. Clin Genet 1980;18:456-61.

4 Carpenter NJ, Say B, Barber ND. A homozygote for pericentric inversion of chromosome 4. F Med Genet 1982;19:469-71.

5 Nicholls RD, Knoll JHM, Butler MG, Karam S, Lalande M. Genetic imprinting suggested by maternal heterodisomy in non deletion Prader-Willi syndrome. Nature 1989;342:281-5.

6 Malcom S, Clayton-Smith J, Nichols M, et al. Uniparental paternal disomy in Angelman's syndrome. Lancet 1991;337: 694-7.

7 Wang JC, Passage MB, Yen P, Shapiro LJ, Mohandes TK. Uniparental heterodisomy for chromosome 14 in a phenotypically abnormal familial 13/14 Robertsonian translocation carrier. Am $\mathcal{Y}$ Hum Genet 1990;47(suppl):99A.

8 Spence JE, Perciaccante RG, Greig GM, et al. Uniparental disomy as a mechanism for human genetic disease. $\mathrm{Am} \mathcal{F} \mathrm{Hum}$ Genet 1988;42:217-26.

9 Voss R, Ben-Simon E, Avital A, et al. Isodisomy of chromosome 7 in a patient with cystic fibrosis: could uniparental disomy be common in humans? Am $\mathcal{F}$ Hum Genet 1989;45:373-80.

10 Cattanach BM. Parental origin effects in mice. $\mathcal{F}$ Embryol Exp Morphol 1986;97 (suppl):137-50.

11 Cattanach BM, Kirk M. Differential activity of maternally and paternally derived chromosome regions in mice. Nature 1985; 315:496-8.

12 Warburton D. Editorial. Uniparental disomy: a rare consequence of the high rate of aneuploidy in human gametes. Am $\mathcal{f} \mathrm{Hum}$ Genet 1988;42:215-6.

13 Ropers HH, Craig IW. Report of the committee on the genetic constitution of chromosomes 12 and 13. HGM10. Cytogenet Cell Genet 1989;51:259-79.

14 Cox DW, Donlon TA. Report of the committee on the genetic constitution of chromosomes 14 and 15. HGM10. Cytogenet Cell Genet 1989;51:280-98.

15 Searle AG, Peters J, Lyon MF, et al. Chromosome maps of man and mouse IV. Ann Hum Genet 1989;53:89-140. 